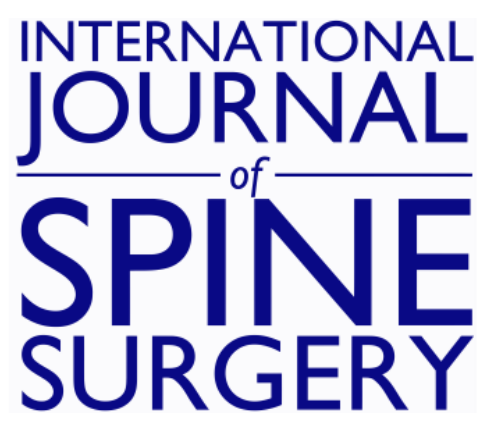

\title{
Arthrodesis Rate and Patient Reported Outcomes After Anterior Lumbar Interbody Fusion Utilizing a Plasma-Sprayed Titanium Coated PEEK Interbody Implant: A Retrospective, Observational Analysis
}

Joseph A. Sclafani, Sophea R. Bergen, Miranda Staples, Kevin Liang and Ramin Raiszadeh

Int J Spine Surg 2017, 11 (1)

doi: https://doi.org/10.14444/4004

http://ijssurgery.com/content/11/1/4

This information is current as of April 26, 2023.

Email Alerts Receive free email-alerts when new articles cite this article. Sign up at:

http://ijssurgery.com/alerts

The International Journal of Shine Sybrgerthttp://ijssurgery.com/ by guest on April 26, 20 2397 Waterbury Circle, Suite 1,

Aurora, IL 60504, Phone: +1-630-375-1432

(C) 2017 ISASS. All Rights Reserved. 


\section{Arthrodesis Rate and Patient Reported Outcomes After Anterior Lumbar Interbody Fusion Utilizing a Plasma-Sprayed Titanium Coated PEEK Interbody Implant: A Retrospective, Observational Analysis.}

Joseph A. Sclafani, MD, 1,2 Sophea R. Bergen, PA-C,1 Miranda Staples, Ph.D, ${ }^{2}$ Kevin Liang, Ph.D, ${ }^{2}$ Ramin Raiszadeh, MD ${ }^{1}$

${ }^{1}$ Spine Institute of San Diego, Minimally Invasive Spine Center of Excellence, San Diego, CA, 2Milestone Research Organization, San Diego, CA.

\section{Abstract}

Background

Anterior lumbar interbody fusion (ALIF) is utilized in symptomatic spinal disc destabilization due to degenerative lumbar disc disease, isthmic and degenerative spondylolisthesis, internal disc disruption, or pseudarthrosis after non-operative treatments fail. The addition of a plasma-sprayed titanium coating (PTC) to polyether ether ketone spacers (PEEK) may reduce the rate of implant subsidence or non-union secondary to poor osseous-integration of non-coated PEEK or metal interbody systems.

\section{Methods}

A retrospective, non-randomized, single-center chart review, evaluated the post-surgical follow-up data of patients receiving a PTC PEEK implant during single or multi-level ALIF procedures to determine the clinical efficacy and rate of arthrodesis after utilization of a coated spacer. Standard roentgenographs or computed tomography were used to identify successful arthrodesis following the ALIF procedure and longitudinal clinical improvements were determined by scores on the Visual Analog Scale (VAS) for low back and leg pain.

Results

Forty-four subjects ( $48 \%$ male, mean $=53$ years) were included in this chart review. Follow-up radiology demonstrated radiographic union with bridging bone formation across the interbody space for $42 / 44$ (96\%) individuals with solid arthrodesis occurring at an average of $7.3 \pm 2.3$ months. Subjects demonstrated significant improvement in VAS low back pain $(4.5 \pm 2.4$ point improvement, $\mathrm{p}=0.0001)$ and VAS leg pain $(4.1 \pm 3.3$ point improvement, $\mathrm{p}=0.0001$ ). While there was a significant reduction in the improvement of VAS low back pain of Worker's Compensation claimants as compared to other patients $(3.9 \pm 2.4$ vs. $5.3 \pm 2.1)$, there was no difference in VAS low back pain or leg pain when the data was stratified by gender, age, tobacco use, comorbidities, prior surgery, fusion construct length, use of supplemental posterior instrumentation, BMI, or diagnosis.

\section{Conclusions}

This study provides support that the addition of a PTC coating to a zero-profile PEEK lumbar interbody spacer facilitates rapid and stable fixation at the bone-implant interface. This facilitated osteogenesis is associated with significantly improved pain outcomes, low implant subsidence and a high definitive rate of arthrodesis. Future studies should include a prospective, randomized, controlled, multi-center approach to directly compare arthrodesis rates and clinical outcomes longitudinally between standard PEEK and biomaterial-coated PEEK interbody spacer systems. 


\section{Introduction}

Anterior lumbar interbody fusion (ALIF) is a commonly utilized procedure in the treatment of degenerative lumbar disc disease, instabilities including isthmic and degenerative spondylolisthesis, internal disc disruption, and repair of symptomatic pseudarthrosis. ${ }^{1.5}$ Key advantages of an anterior interbody fusion approach over posterior approaches include the preservation of paraspinal muscle architecture, the ability to perform a more extensive discectomy, and placement of a larger interbody implant. ${ }^{1,6}$ However, anterior reconstructive approaches require an approach surgeon and have been infrequently associated with post-operative sympathetic dysfunction and retrograde ejaculation. ${ }^{7-10}$

Early ALIF interbody spacer systems were composed of incompressible metals that often subsided when subjected to routine biomechanical forces of the anterior vertebral column. ${ }^{1-13}$ Subsequent generations of implantable spacer systems were made of nonabsorbable biomaterials with elastic properties such as polyether ether ketone (PEEK). ${ }^{14}$ These systems were able to better accommodate physiologic loadbearing which was demonstrated to greatly improve subsidence rates over metal composite systems."

Although PEEK systems provide biomechanical advantages over their metal interbody predecessors, implant subsidence continued to occur after anterior lumbar reconstructive procedures secondary to poor osseous-integration properties of the PEEK biomaterial. ${ }^{15.17}$ Walsh et al. has recently demonstrated that application of a plasma-sprayed titanium coating to PEEK spacers (PTC PEEK) facilitates direct bone ongrowth at cortical and cancellous sites using an ovine model system. ${ }^{18}$ As a result of improved fixation, PTC PEEK interbody spacer systems were found to be superior to PEEK spacers in resisting shear forces as early as four weeks after implantation.

The clinical study that follows was conducted to investigate the effectiveness of a PTC PEEK interbody implant in promoting successful arthrodesis after anterior lumbar interbody fusion. This was evaluated using either standard radiographs or computed tomography (CT) in addition to longitudinal improve- ments in VAS (visual analog scale) for low back and leg pain within a diverse population.

\section{Methods}

A retrospective, non-randomized, single-center chart review was conducted for a series of patients treated with a locking, plasma-sprayed titanium coated PEEK interbody implant during anterior lumbar interbody fusion (Magnum+ Stand-Alone No Profile Interbody Spacer System with Ti-Bond Coating; Spinal Elements, Inc., Carlsbad, CA, USA, Figure 1) with at least six months of post-surgical follow-up data. A mixture of bone morphogenic protein (Infuse; Medtronic, Minneapolis, MN, USA), cancellous bone chips, and local autograft was used to support successful arthrodesis in every case. All races, socioeconomic classes, and genders were included for analysis. Exclusion criteria included individuals aged less than 18 or greater than 90 years old. A single, fellowship-trained surgeon (RR) performed every procedure.

Following Institutional Review Board approval, preoperative patient demographics (age, gender, BMI, diagnosis, comorbidities, previous surgeries, surgical approach, Visual Analog Pain Scale (VAS) for both low back and radiating leg pain, workers' compensation claim status, tobacco use) were collected through a retrospective chart review. Perioperative data including operative levels, intraoperative complications and implant specifications were obtained from available operative reports and hospital discharge summaries. Post-operative data collection in-

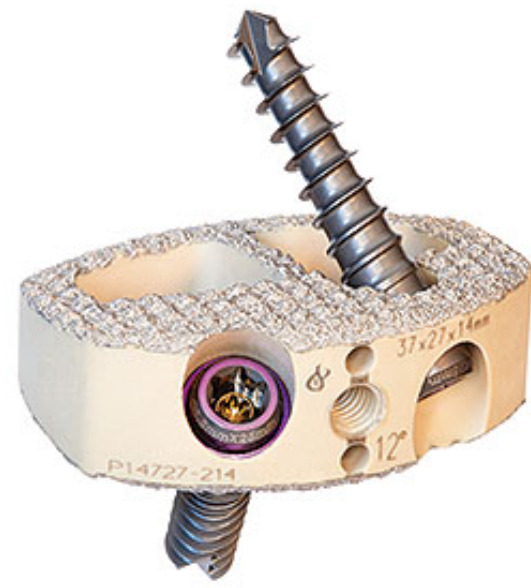

Fig. 1. The PTC PEEK interbody spacer system implanted in this study. 
cluded $9 \pm 3$ months post-operative low back and radiating leg VAS pain scores, evidence of solid arthrodesis on radiographic reports (utilizing either standard radiographs or computed tomography) interpreted by an independent Radiologist, and incidence of reoperation up to one year post-op. Interbody subsidence was reported if there was $25 \%$ or greater loss of postoperative disc height, measured by the authors of this paper.

All data were electronically collected through a sequential series chart review and de-identified prior to analysis by an independent clinical research organization. Data were segmented for analysis based on sex, age ( $<55$ years versus $\geq 55$ years), procedure, comorbidities including tobacco use, diagnosis, surgical level, use of supplemental posterior instrumentation, workers' compensation claim status, and BMI ( $<30$ versus $\geq 30$ ). Statistical analyses were performed through two-tailed paired and unpaired t-tests. Data are reported as mean \pm standard deviation with significance defined as $\mathrm{p}<0.05$.

\section{Results}

There were 44 subjects ( 21 male, 23 female) with a mean age of 53 years (range: $33-77$ years) at the time of surgery included in this retrospective analysis. One subject did not have available pre or postoperative VAS pain scores and was therefore only included in arthrodesis status analysis. A total of 7/44 (16\%) subjects were treated with an ALIF at the level of a previous decompression procedure, two subjects were treated with an ALIF at an adjacent segment, and one subject underwent a previous spinal cord stimulator implantation. Single-level procedures were performed on 24/44 (55\%) subjects and multiple-level procedures were completed on $20 / 44$ (46\%) subjects. The primary diagnosis of a spondylolisthesis was assigned to $25 / 44$ (57\%) subjects. Nine subjects (20\%) reported tobacco use during the post-operative follow-up period. The mean overall BMI was 29.9 (range: 21.0-43.6) and 25/44 (57\%) subjects were affected by a metabolic comorbidity (hypertension, diabetes mellitus, or cardiovascular disease). Twenty-six patients (59\%) were treated under a Worker's Compensation claim (Table 1).
A single $14 \mathrm{~mm}$ spacer was used in $12 / 44$ (27\%), a single $16 \mathrm{~mm}$ spacer in $12 / 44(27 \%)$, multiple $14 \mathrm{~mm}$ spacers in 6/44 (14\%), multiple 16mm spacers in $4 /$ $44(9 \%)$, both $12 \mathrm{~mm}$ and $14 \mathrm{~mm}$ spacers in $1 / 44(3 \%)$, both $14 \mathrm{~mm}$ and $16 \mathrm{~mm}$ spacers in $5 / 44(11 \%)$, both $16 \mathrm{~mm}$ and $18 \mathrm{~mm}$ spacers were used in $2 / 44(5 \%)$, a single $18 \mathrm{~mm}$ spacer in $1 / 44(3 \%)$, and both $18 \mathrm{~mm}$ and $20 \mathrm{~mm}$ spacers were used in $1 / 44$ (3\%) cases. Supplemental posterior instrumentation was inserted in 33/ $44(75 \%)$ and a standalone ALIF was completed in $11 / 44(25 \%)$ subjects. There were no reported peri-

Table 1. Improvement in VAS back and leg scores at 9 months follow-up by subject subgroup.

\begin{tabular}{|c|c|c|c|c|c|}
\hline & $\mathrm{N}$ & $\begin{array}{r}\text { Improvement } \\
\text { (VAS Back) }\end{array}$ & $\begin{array}{r}\mathrm{P} \\
\text { (back) }\end{array}$ & $\begin{array}{r}\text { Improvement } \\
\text { (VAS Leg) }\end{array}$ & P (leg) \\
\hline Overall & 43 & 4.5 & 0.0001 & 4.1 & 0.0001 \\
\hline Age: $<55$ years & 27 & 4.5 & \multirow{2}{*}{0.98} & 3.9 & \multirow{2}{*}{0.47} \\
\hline Age: $>55$ years & 16 & 4.5 & & 4.6 & \\
\hline Female & 23 & 4.4 & \multirow{2}{*}{0.73} & 4.4 & \multirow{2}{*}{0.54} \\
\hline Male & 20 & 4.7 & & 3.8 & \\
\hline No Tobacco Use & 35 & 4.6 & \multirow{2}{*}{0.62} & 4.3 & \multirow{2}{*}{0.55} \\
\hline Tobacco Use & 8 & 4.1 & & 3.5 & \\
\hline $\begin{array}{l}\text { Metabolic } \\
\text { Comorbidity }\end{array}$ & 25 & 4.4 & \multirow{2}{*}{0.82} & 4.3 & \multirow{2}{*}{0.68} \\
\hline $\begin{array}{l}\text { No Metabolic } \\
\text { Comorbidity }\end{array}$ & 18 & 4.6 & & 3.9 & \\
\hline No Prior Surgery & 33 & 4.7 & \multirow{2}{*}{0.44} & 4.1 & \multirow{2}{*}{0.78} \\
\hline Prior Surgery & 10 & 4 & & 4.4 & \\
\hline $\begin{array}{l}\text { Single-Level } \\
\text { Surgery }\end{array}$ & 23 & 4.5 & \multirow{2}{*}{0.93} & 3.7 & \multirow{2}{*}{0.35} \\
\hline $\begin{array}{l}\text { Multilevel } \\
\text { Surgery }\end{array}$ & 20 & 4.6 & & 4.7 & \\
\hline $\begin{array}{l}\text { No Worker's } \\
\text { Comp }\end{array}$ & 18 & 5.3 & \multirow[t]{2}{*}{0.05} & 4.9 & \multirow[t]{2}{*}{0.21} \\
\hline Worker's Comp & 25 & 3.9 & & 3.6 & \\
\hline Standalone ALIF & 11 & 5.2 & \multirow{2}{*}{0.28} & 4.8 & \multirow{2}{*}{0.44} \\
\hline $\mathrm{ALIF}+\mathrm{PSF}$ & 32 & 4.3 & & 3.9 & \\
\hline $\mathrm{BMI}<30$ & 25 & 4.1 & \multirow{2}{*}{0.21} & 4.6 & \multirow{2}{*}{0.33} \\
\hline $\mathrm{BMI}>30$ & 18 & 5.1 & & 3.6 & \\
\hline Spondylolisthesis & 24 & 4.4 & \multirow[b]{2}{*}{0.68} & 3.7 & \multirow[b]{2}{*}{0.34} \\
\hline $\begin{array}{l}\text { No } \\
\text { Spondylolisthesis }\end{array}$ & 18 & 4.7 & & 4.7 & \\
\hline
\end{tabular}


operative complications or adverse events reported that could be attributed to the plasma sprayed titanium coated PEEK spacer. There were two reoperations reported within the twelve-month follow-up period: adjacent segment decompression of HNP with annular tear $(\mathrm{n}=1)$, adjacent segment ALIF $(\mathrm{n}=1)$. A single individual underwent a radiofrequency ablation at the level adjacent to the previous anterior lumbar interbody fusion within the follow-up period. Additionally, one subject underwent an anterior cervical discectomy and fusion within the follow-up period that was unrelated to their previous lumbar arthrodesis procedure.

There was significant improvement in 9-month postoperative VAS low back pain $(4.5 \pm 2.4$ point improvement, $\mathrm{p}=0.0001)$ and VAS leg pain $(4.1 \pm 3.3$ point improvement, $\mathrm{p}=0.0001$ ), as listed in Table 1 . Subjects with open Worker's Compensation claims demonstrated less improvement in 9-month postoperative low back pain scores $(3.9 \pm 2.4$ points $)$ than those with private insurance (5.3 points \pm 2.1 , $\mathrm{p}=0.05$ ) but there was not a significant difference in leg pain improvement between these two groups. There was not a significant difference in VAS low back or leg pain improvement between groups $(p>0.05)$ when the data was stratified by gender, age, tobacco use, comorbidities, prior surgery, fusion construct length, use of supplemental posterior instrumentation, BMI, or diagnosis.

Radiographic union with bridging bone formation across the interbody space was confirmed for $42 / 44$ (96\%) individuals (Table 2, Figure 2). Solid arthrodesis was observed at an average of $7.3 \pm 2.3$ months post-op in the overall cohort. Standard radiographs confirmed a solid arthrodesis in 34/44 (77\%) and by CT imaging in 8/44 (18\%). Both of the two subjects without confirmed arthrodesis displayed intact instrumentation without loosening at three months post-op but were subsequently lost to follow-up. There were no differences in successful arthrodesis rate or time to solid arthrodesis when groups were stratified by gender, age, tobacco use, comorbidities, prior surgery, fusion construct length, use of supplemental posterior instrumentation, BMI, insurance type, or a diagnosis of spondylolisthesis. There were zero reported cases of interbody migration or subsi- dence within the follow-up period.

\section{Discussion}

This study demonstrates that enhancement of appositional stability with a plasma-sprayed titanium coated PEEK ALIF implant promotes safe, rapid bridging bone formation and a low rate of implant subsidence. There was clinically significant improvement in post-operative VAS low back pain and leg pain in all stratified groups, including those with medical or social complexities (use of tobacco products). ${ }^{20,21}$ Successful arthrodesis with bridging bone formation was observed in $96 \%$ of all cases with the remaining $4 \%$ demonstrating signs of early fusion before being lost

\begin{tabular}{|c|c|c|c|}
\hline & $\mathrm{N}$ & $\begin{array}{l}\text { Months to } \\
\text { Fusion }\end{array}$ & $\begin{array}{r}P \text { value (time to } \\
\text { fusion) }\end{array}$ \\
\hline Overall & 44 & 7.3 & \\
\hline Age: $<55$ years & 28 & 7.3 & \multirow{2}{*}{0.86} \\
\hline Age: $>55$ years & 16 & 7.2 & \\
\hline Female & 23 & 7.3 & 0.97 \\
\hline Male & 21 & 7.3 & \\
\hline No Tobacco Use & 35 & 7.3 & \multirow{2}{*}{0.96} \\
\hline Tobacco Use & 9 & 7.3 & \\
\hline Metabolic Comorbidity & 25 & 7.1 & \multirow{2}{*}{0.51} \\
\hline $\begin{array}{l}\text { No Metabolic } \\
\text { Comorbidity }\end{array}$ & 19 & 7.6 & \\
\hline No Prior Surgery & 34 & 7.4 & \multirow{2}{*}{0.44} \\
\hline Prior Surgery & 10 & 6.8 & \\
\hline Single-level Surgery & 24 & 7.3 & \multirow{2}{*}{0.85} \\
\hline Multilevel Surgery & 20 & 7.2 & \\
\hline No Worker's Comp & 18 & 7.4 & \multirow{2}{*}{0.84} \\
\hline Worker's Comp & 26 & 7.2 & \\
\hline Standalone ALIF & 11 & 7.4 & \multirow{2}{*}{0.86} \\
\hline $\mathrm{ALIF}+\mathrm{PSF}$ & 33 & 7.3 & \\
\hline $\mathrm{BMI}<30$ & 26 & 7.6 & \multirow{2}{*}{0.33} \\
\hline $\mathrm{BMI}>30$ & 18 & 6.9 & \\
\hline Spondylolisthesis & 25 & 7.5 & \multirow{2}{*}{0.49} \\
\hline No Spondylolisthesis & 19 & 7 & \\
\hline
\end{tabular}


to follow-up. Subgroups at high risk for pseudarthrosis (tobacco users, obese, advanced age, and metabolic comorbidities) demonstrated similar solid fusion rates and time to fusion compared to lower risk subgroups. There were zero observed cases of implant migration or incomplete bone-implant apposition and zero perioperative safety events reported.

The observed rate of solid fusion with a PTC PEEK implant in this study represents an improvement over previous studies of standard PEEK interbody spacers. Behrbalk et al. reported a $90.6 \%$ solid fusion rate at 18 months after stand-alone PEEK ALIF with supplemental $\mathrm{BMP}^{\mathrm{11}}$ and Schimmel et al. reported a symptomatic pseudarthrosis occurred in $24 \%$ of individuals treated with ALIF and a standard PEEK interbody spacer. ${ }^{12}$ Additionally, time to solid fusion within this study ( $x=7.3 \pm 2.3$ months) also occurred more rapidly than what has been observed in pub-

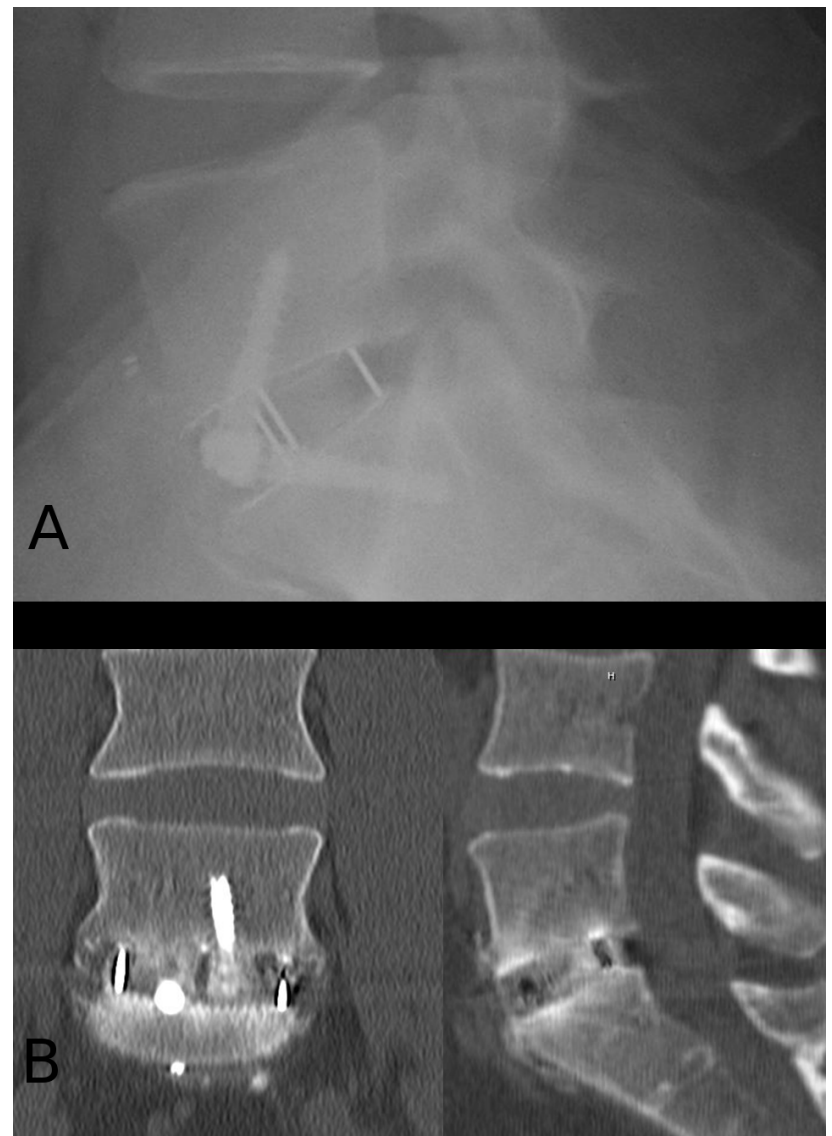

Fig. 2. A) Three month post-op standing lateral radiograph demonstrating early bridging bone formation across the PTC PEEK spacer. B) Six month post-op CT coronal and sagittal images of the same subject demonstrating solid arthrodesis. lished studies of standard PEEK ALIF implants. Behrbalk et al. reported $88 \%$ of subjects without a spondylolisthesis and only $43 \%$ with a spondylolisthesis achieved solid fusion at a similar post-op time interval. ${ }^{11}$ Additionally, the absence of any observed subsidence with PTC PEEK spacers in this study compares favorably to reported subsidence rates of 16-25\% with standard PEEK ALIF implantation. ${ }^{11,22,33}$

There was clinically significant improvement in VAS low back and leg pain scores at the $9 \pm 3$ month postoperative follow-up visit for all stratified PTC PEEK subgroups. While there was statistically less improvement in VAS low back pain for individuals obtaining treatment under a Worker's Compensation claim compared to those with private insurance or Medicare benefits, it is worth noting that Worker's Compensation has previously been associated with significant, consistently poor clinical outcomes after surgical treatment and is therefore widely regarded as a potentially confounding variable. ${ }^{24}$ There was not a significant difference in VAS back or leg outcomes between any other subgroup, including subjects with previous lumbar spine surgery, metabolic comorbidities, or advanced age.

The retrospective, single-site study design of this study presents several inherent limitations. First, all cases were performed by a single experienced, fellowship trained spine surgeon within a recognized Spine Center of Excellence. This limits generalizability of these results to less experienced surgeons or those that may operate on a more complex/diverse patient population in the setting of a less specialized healthcare center. Second, data was collected within accordance to an accepted standard of care treatment algorithm. As a result, only a small subset of the cohort underwent post-operative lumbar CT imaging to confirm complete arthrodesis. This required less sensitive imaging modalities to be used to confirm solid fusion for most subjects. Lastly, this retrospective observational cohort study did not include a control group treated with ALIF and a standard PEEK interbody implant to compare patient-reported outcomes and solid arthrodesis rates.

The successful outcomes of this study should be used to drive future investigation of clinical benefits 
associated with the application of a plasma-sprayed titanium biomaterial coating to PEEK interbody implants. Our results support that PTC PEEK interbody spacers facilitate rapid and stable fixation at the bone-implant interface, facilitating low implant subsidence and high arthrodesis rates. For future studies, a prospective, randomized, controlled, multi-center approach should be utilized to directly compare arthrodesis rates and clinical outcomes longitudinally between standard PEEK and biomaterial-coated PEEK interbody spacer systems with standardized, sensitive imaging modalities, as the evidence from this study and others suggests that the addition of biomaterial coating to PEEK interbody spacer systems significantly improves clinical outcomes for a wide range of patients.

\section{References}

1. Crock H. Anterior lumbar interbody fusion: indications for its use and notes on surgical technique. Clinical orthopaedics and related research 1982;165:157-63.

2. Newman MH, Grinstead GL. Anterior lumbar interbody fusion for internal disc disruption. Spine 1992;17:831-3.

3. Smith GW, Robinson RA. The treatment of certain cervical-spine disorders by anterior removal of the intervertebral disc and interbody fusion. The Journal of bone and joint surgery American volume 1958;40:607-24.

4. Zdeblick TA, David SM. A prospective comparison of surgical approach for anterior L4-L5 fusion: laparoscopic versus mini anterior lumbar interbody fusion. Spine 2000;25:2682-7.

5. Ishihara H, Osada R, Kanamori M, et al. Minimum 10-year follow-up study of anterior lumbar interbody fusion for isthmic spondylolisthesis. Journal of Spinal Disorders \& Techniques 2001;14:91-9.

6. Greenough CG, Peterson MD, Hadlow $S$, Fraser RD. Instrumented posterolateral lumbar fusion: results and comparison with anterior interbody fusion. Spine 1998;23:479-86.

7. Lindley EM, McCullough MA, Burger EL, Brown CW, Patel VV. Complications of axial lumbar interbody fusion: Clinical article. Journal of Neurosurgery: Spine 2011;15:273-9.
8. Rajaraman V, Vingan R, Roth P, Heary RF, Conklin L, Jacobs GB. Visceral and vascular complications resulting from anterior lumbar interbody fusion. Journal of Neurosurgery: Spine 1999;91:60-4. 9. Villavicencio AT, Burneikiene S, Bulsara KR, Thramann JJ. Perioperative complications in transforaminal lumbar interbody fusion versus anterior-posterior reconstruction for lumbar disc degeneration and instability. Journal of spinal disorders \& techniques 2006;19:92-7.

10. Sasso RC, Burkus JK, LeHuec J-C. Retrograde ejaculation after anterior lumbar interbody fusion: transperitoneal versus retroperitoneal exposure. Spine 2003;28:1023-6.

11. Behrbalk E, Uri O, Parks RM, Musson R, Soh RCC, Boszczyk BM. Fusion and subsidence rate of stand alone anterior lumbar interbody fusion using PEEK cage with recombinant human bone morphogenetic protein-2. European Spine Journal 2013;22:2869-75.

12. Schimmel JJ, Poeschmann MS, Horsting PP, Schönfeld DH, van Limbeek J, Pavlov PW. PEEK Cages in Lumbar Fusion: Mid-term Clinical Outcome and Radiologic Fusion. Clinical spine surgery 2016;29:E252-E8.

13. Spruit M, Falk R, Beckmann L, Steffen T, Castelein $R$. The in vitro stabilising effect of polyetheretherketone cages versus a titanium cage of similar design for anterior lumbar interbody fusion. European Spine Journal 2005;14:752-8.

14. Galbusera F, Schmidt H, Wilke H-J. Lumbar interbody fusion: a parametric investigation of a novel cage design with and without posterior instrumentation. European Spine Journal 2012;21:455-62.

15. Kurtz SM, Devine JN. PEEK biomaterials in trauma, orthopedic, and spinal implants. Biomaterials 2007;28:4845-69.

16. Ma R, Tang T. Current strategies to improve the bioactivity of PEEK. International journal of molecular sciences 2014;15:5426-45.

17. Wu SH, Li Y, Zhang YQ, et al. Porous Titanium-6 Aluminum-4 Vanadium Cage Has Better Osseointegration and Less Micromotion Than a Poly-Ether-Ether-Ketone Cage in Sheep Vertebral Fusion. Artificial organs 2013;37:E191-E201. 18. Walsh WR, Bertollo N, Christou C, Schaffner D, Mobbs RJ. Plasma-sprayed titanium coating to 
polyetheretherketone improves the bone-implant interface. The Spine Journal 2015;15:1041-9.

19. Marchi L, Abdala N, Oliveira L, Amaral R, Coutinho E, Pimenta L. Radiographic and clinical evaluation of cage subsidence after stand-alone lateral interbody fusion: Clinical article. Journal of Neurosurgery: Spine 2013;19:110-8.

20. Beurskens AJ, de Vet HC, Koke AJ. Responsiveness of functional status in low back pain: a comparison of different instruments. Pain 1996;65:71-6. 21. Hagg O, Fritzell P, Nordwall A, Swedish Lumbar Spine Study G. The clinical importance of changes in outcome scores after treatment for chronic low back pain. European spine journal : official publication of the European Spine Society, the European Spinal Deformity Society, and the European Section of the Cervical Spine Research Society 2003;12:12-20.

22. Carragee EJ, Hurwitz EL, Weiner BK. A critical review of recombinant human bone morphogenetic protein-2 trials in spinal surgery: emerging safety concerns and lessons learned. The Spine Journal 2011;11:471-91.

23. Mroz TE, Wang JC, Hashimoto R, Norvell DC. Complications related to osteobiologics use in spine surgery: a systematic review. Spine

2010;35:S86-S104.

24. Harris I, Mulford J, Solomon M, van Gelder JM, Young J. Association between compensation status and outcome after surgery: a meta-analysis. Jama 2005;293:1644-52.

\section{Disclosures \& COI}

Sophea Bergen reports no relevant disclosures or conflicts of interest. Kevin Liang is an employee of MileStone Research Organization, a third party clinical research company contracted by Spinal Elements to assist with the research. Neither Kevin Liang nor MileStone Research have any financial ties, direct or indirect, to outcomes or data presented in this publication. Ramin Raiszadeh declares no relevant disclosures or conflicts of interest. Joseph A. Sclafani is consultant to MileStone Research Organization, a third party clinical research company contracted by Spinal Elements to assist with this research. Neither Joseph Sclafani or MileStone research have any financial interest with respect to outcomes or data presented in this publication. Miranda Staples is an employee of MileStone Research Organization, a third party clinical research company contracted by Spinal Elements to assist with this research. Neither Miranda Staples nor MileStone Research have any financial ties, direct or indirect, to outcomes or data presented in this publication.

\section{Corresponding Author}

Joseph A. Sclafani, MD. jsclafani61@icloud.com.

Published 13 January 2017.

This manuscript is generously published free of charge by ISASS, the International Society for the Advancement of Spine Surgery. Copyright @ 2017 ISASS. To see more or order reprints or permissions, see http://ijssurgery.com. 